\title{
A correlational study of ultrasound diagnosis with clinical and operative diagnosis in causes of complications in first trimester
}

\author{
Ravi Kumar Manipati ${ }^{1 *}$, Sai Ram Moravaneni ${ }^{2}$ \\ ${ }^{1}$ Assistant Professor, ${ }^{2}$ Consultant Radiologist, Department of Radiodiagnosis, Apollo Medical College, Chittoor, INDIA. \\ Email: raviradio2k11@gmail.com
}

\begin{abstract}
Background: The pathologies occurring in early pregnancy are common but some may be life threatening and it is therefore essential to promptly diagnose and treat complications to achieve the best fetal and maternal outcomes. Aim and objective: To correlate the ultrasound diagnosis with clinical and operative diagnosis in causes of complications in first trimester. Methodology: Present study was a prospective study carried out in the fifty women, who presented with symptoms in first trimester such as vaginal spotting or bleeding, pain abdomen in the first trimester of pregnancy referred to sonography department. All patients underwent transvaginal and transabdominal ultrasonography. These findings were correlated with clinical diagnosis and operative diagnosis of the patients. Data was analysed with appropriate statistical tests. Results: In threatened abortion ultrasound had accuracy rate of $100 \%$, while clinical accuracy was 54\%.In missed abortion, ultrasound has accuracy rate of $100 \%$. While clinical accuracy is only $4 \%$. In incomplete abortions, the clinical accuracy rate is $24 \%$ while ultrasound had an accuracy of $100 \%$. In complete abortion ultrasound has accuracy rate of 100 $\%$. While clinical accuracy is only $6 \%$. In cases of ectopic pregnancy, Clinical accuracy was $8 \%$ while ultrasound accuracy was only $70 \%$. Out of the two clinically diagnosed cases of vesicular mole, only one was sonologically diagnosed as vesicular mole with an accuracy rate of $100 \%$. Clinical diagnosis was only $4 \%$ accurate.

Key Word: clinical and operative diagnosis.
\end{abstract}

*Address for Correspondence:

Dr Ravi Kumar Manipati, Assistant Professor, Department of Radiodiagnosis, Apollo Medical College, Chittoor, INDIA.

Email: raviradio2k11@gmail.com

Received Date: 20/04/2020 Revised Date: 12/05/2020 Accepted Date: 17/06/2020

DOI: https://doi.org/10.26611/10131511

This work is licensed under a Creative Commons Attribution-NonCommercial 4.0 International License. (cc) EY-NC

\begin{tabular}{|l|l|}
\hline \multicolumn{2}{|c|}{ Access this article online } \\
\hline Quick Response Code: & Website: \\
\cline { 1 - 2 } & www.medpulse.in \\
& Accessed Date: \\
& \\
\hline
\end{tabular}

\section{INTRODUCTION}

First trimester pregnancy is the initial 12 weeks of the pregnancy, which is the most crucial time in both the women and the growing fetus, since they are more prone to face complications such as, spotting, pervaginal bleeding and pain abdomen which represents a definite threat to the developing embryo / fetus and constitute a source of anxiety both to the women and her clinician. Most common symptoms with which patients present with, in the first trimester are: spotting, vaginal bleeding, pelvic/abdominal pain, dysuria and frequency of micturition. Bleeding per vaginum is a relatively common event in the first trimester, reported to occur in $15 \%$ to $25 \%$ of all pregnancies. ${ }^{1-8}$ The detection and the diagnosis of causes of first trimester bleeding per vaginum, based on the clinical examination alone is often inconclusive and doubtful, therefore there is a need for further evaluation by non invasive methods such as ultrasonography. Real time sonography is a noninvasive modality that is extremely useful to arrive at an accurate diagnosis. Nearly i.e. 27$30 \%$ of all pregnant women in their first trimester complain of bleeding per vaginum. In these women who present with bleeding per vagina, during their first trimester, several diagnostic possibilities can be considered. The differential diagnosis includes 1 . Threatened abortion with a viable intrauterine pregnancy 2. Missed abortion 3. Incomplete abortion 4. Complete abortion 5. Ectopic pregnancy 6. Gestational trophoblastic disease Ultrasound in women who presents with the bleeding in the first trimester helps 1. In confirming the pregnancy. 2. To know if the 
pregnancy is intrauterine or extrauterine. 3. To assess the period of gestation. 4. In early recognization of any associated pelvic abnormality. 5. To confirm the viability of the fetus. 6. To confirm or rule out suspected molar pregnancy. 7. To assess causes of first trimester pregnancy failure such as blighted ovum, incomplete, complete or missed abortion 8.To rule out other pelvic causes for bleeding.

The aim of this study is to evaluate role of ultrasonography in prospective evaluation of causes in symptomatic first trimester pregnancy.

\section{MATERIAL AND METHODS}

Present study was a prospective study carried out in the department of Radiodiagnsois, MVJMC nad RH during November 2011 to August 2013. Study population was Fifty women, who presented with symptoms in first trimester such as vaginal spotting or bleeding, pain abdomen in the first trimester of pregnancy referred to our department for sonography.

Inclusion criteria: 1.Positive pregnancy test. 2.First trimester up to 12 weeks of embryonic gestational age. 3 . Chief complaint of at least one of the following: vaginal spotting / bleeding, pain abdomen.

\section{Exclusion criteria:}

1. Asymptomatic patients in the first trimester.

2. All the patients with more than 12 weeks gestation.

3. Patient presenting with profuse bleeding necessitating emergency evacuation.

4. Patient who refuse to get admitted in the hospital. Study was approved by ethical committee of the institute. A valid written consent was taken from the patients after explaining study to them. Machine used for examination was GE VOLUSION 730 PRO machine. Curvilinear array transducer with frequency of 2- $6 \mathrm{MHz}$ was used for TAS. Transvaginal probe of frequency $7-10 \mathrm{MHz}$ for TVS.

For all the examinations in this study full bladder technique was used for Transabdominal scans and empty bladder technique for transvaginal scans. The curvilinear probe was placed in the suprapubic region over the bladder and was angled caudally to obtain longitudinal section of the uterus, cervix and vagina. Then the orientation was changed to transverse, to study the adnexal regions by angling the probe gently form caudal to cranial end by 15 - 20 degrees. While doing so, vaginal walls, cervix and body of the uterus were studied. For the transvaginal scan the patient was placed in the lithotomy position having emptied her bladder. The transvaginal probe is covered with a protective sheath, usually a surgical glove and adequate coupling gel is applied. The transducer is inserted in the vagina. Initially a longitudinal scan was done followed by a transverse scan. During examination, the size, shape, version of the uterus were noted. The presence or absence of the gestational sac and if present its size, shape and its measurement were taken to obtain the mean sac diameter. When the presence of the sac was ascertained, then the presence or absence of the foetal node was looked for. If the sac was empty, its shape and gestational age were calculated. If the fetal node was seen then it was observed foe the fetal cardiac activity, fetal movements and any other obvious congenital anomalies. Depending on the observation, appropriate measurements of the gestational age were obtained i.e., CRL or BPD. Patients in whom scan was done late in first trimester, location of the placenta, its maturity and evidence of hemorrhage if any were noted. Lastly adnexal region was scanned to confirm or rule out ectopic pregnancy, to look for any collection in the pouch of Douglas and to see if there are any masses. All the cases of threatened abortion were followed up and the rest with pregnancy were managed accordingly. Statistical analysis was done in EPI6 statistical soft ware.

\section{RESULTS}

In the present study, the majority of the patients were in the age group of 26-30 years, totaling $17(36 \%), 16$ patients $(32 \%)$ were of $20-25$ years, 11 patients $(21 \%)$ were less than 20 years, 6 patients $(11 \%)$ were above 30 years. In the present study, 28 women (56\%), with more than 10 weeks of amenorrhea, complained of bleeding. The least problematic period was $8-10$ weeks during which period of pregnancy only 6 patients $(12 \%)$ has bleeding, 16 cases (32\%) less than 8 weeks complained of bleeding. In the present study, clinically 27 cases (54\%) were diagnosed as threatened abortion, 12 cases $(24 \%)$ as incomplete abortion, 4 cases ( $8 \%$ ) as ectopic pregnancy, 3 cases $(6 \%)$ as complete abortion, 2 cases ( $4 \%$ ) as missed abortion, 2 cases $(4 \%)$ as gestational trophoblastic disease. (table 1) In the present study, Out of the 50 cases, ultrasound diagnosis of threatened abortion was made in 18 patients(36\%), missed abortion in 12 patients $(24 \%)$, incomplete abortion in 11 patients $(22 \%)$, complete abortion in 5 patients(10\%), ectopic pregnancy in 5 patients(6\%)and gestational trophoblastic disease in 1 patient $(2 \%)$. (table 2) By correlating clinical and ultrasound diagnosis, it was found that there was disparity between the two diagnosis. The disparity was more for threatened abortion, missed abortion, and complete abortion. Clinically it was not possible to diagnose blighted ovum, complete and inevitable abortions. So ultrasound examination had an upper hand in diagnosis of these cases. The total number of disparities between clinical and ultrasound diagnosis of the causes of bleeding in first trimester was 24 and the percentage of disparity is $44.4 \%$. (table 3) 
The accuracy of the ultrasound compared to that of clinical diagnosis was $100 \%$ in detection of threatened abortion, blighted ovum, incomplete abortion, complete abortion and gestational trophoblastic disease. It was found that the accuracy of $70 \%$ in the diagnosis of ectopic pregnancy. One case of the 4 ectopic pregnancies was wrongly diagnosed as Tubo ovarian mass by ultrasound examination. Out of 18 cases that were sonologically diagnosed as threatened abortion, 12 continued as normal pregnancy, two opted for MTP and tubectomy and 2 underwent dilatation and curettage. Out of the 12 patients who continued pregnancy, 11 had full term normal deliveries and one patient underwent emergency LSCS for foetal distress. The infants were healthy, no congenital anomalies were seen. Out of 12 cases 9 cases were diagnosed as embryonal demise and 3 were diagnosed as blighted ovum. The accuracy of ultrasound in diagnosis of missed abortion is $100 \%$. Of the 11 cases of incomplete abortions diagnosed by ultrasound all were correctly diagnosed. Of the 5 cases of complete abortions diagnosed by ultrasound, all were correctly diagnosed. So in the diagnosis of complete and incomplete abortions, ultrasound has an accuracy of $100 \%$. Out of 3 cases of ectopic pregnancy, 2 cases were correctly diagnosed by ultrasound, another was misdiagnosed as Tuboovarian mass and was proved to be ectopic pregnancy in laporotomy. Ultrasound has an accuracy of $70 \%$ in the present study in the diagnosis of ectopic pregnancy. Of the one case of vesicular mole, it was correctly diagnosed as vesicular mole on evacuation. Ultrasound has an accuracy of $100 \%$ in the detection of vesicular mole in the present study.

\begin{tabular}{cc} 
Table 1: Distribution of 50 cases of present study based on clinical diagnosis \\
\hline Clinical diagnosis & No. Of cases \\
\hline Threatened abortion & 27 \\
Incomplete abortion & 12 \\
Ectopic pregnancy & 04 \\
Complete abortion & 03 \\
Missed abortion & 02 \\
Gestational trophoblastic disease & 02 \\
\hline TOTAL & 50 \\
\hline
\end{tabular}

Table 2: Distribution of 50 cases of present study based on ultrasonological diagnosis

\begin{tabular}{cc}
\hline Ultrasound diagnosis & No. Of cases \\
\hline Threatened abortion (normal pregnancy + intrauterine & $(12+6)=18$ \\
hematoma) & \\
Missed abortion (Embryonal demise + Blighted ovum) & $(9+3)=12$ \\
Incomplete abortion (Retained products of conception) & 11 \\
Complete abortion & 05 \\
Ectopic pregnancy & 03 \\
Gestational trophoblastic disease & 01 \\
\hline TOTAL & 50 \\
\hline
\end{tabular}

Table 3: Correlation of number of cases based on ultrasound and clinical diagnosis

\begin{tabular}{cccc}
\hline CASES & CLINICAL DIAGNOSIS & USG DIAGNOSIS & DISPARITY \\
\hline Threatened abortion & 27 & 18 & 9 \\
Missed abortion & 02 & 12 & 10 \\
Incomplete abortion & 12 & 11 & 1 \\
Complete abortion & 03 & 05 & 2 \\
Ectopic pregnancy & 04 & 03 & 1 \\
Gest.Trophoblastic & 02 & 01 & 1 \\
Disease & & & 24 \\
\hline TOTAL & 50 & 50 & \\
\hline
\end{tabular}

Table 4: Comparision of clinical and ultrasound diagnostic accuracy

\begin{tabular}{ccc}
\hline No. of Cases & Clinical accuracy rate & USG accuracy rate \\
\hline Threatened abortion & $54 \%$ & 100 \\
Missed abortion & $4 \%$ & 100 \\
Complete abortion & $6 \%$ & 100 \\
Incomplete abortion & $24 \%$ & 100 \\
Ectopic pregnancy & $8 \%$ & 70 \\
Gest.tropho.disease & $4 \%$ & 100 \\
\hline
\end{tabular}


Table 5: Follow up of cases diagnosed clinically

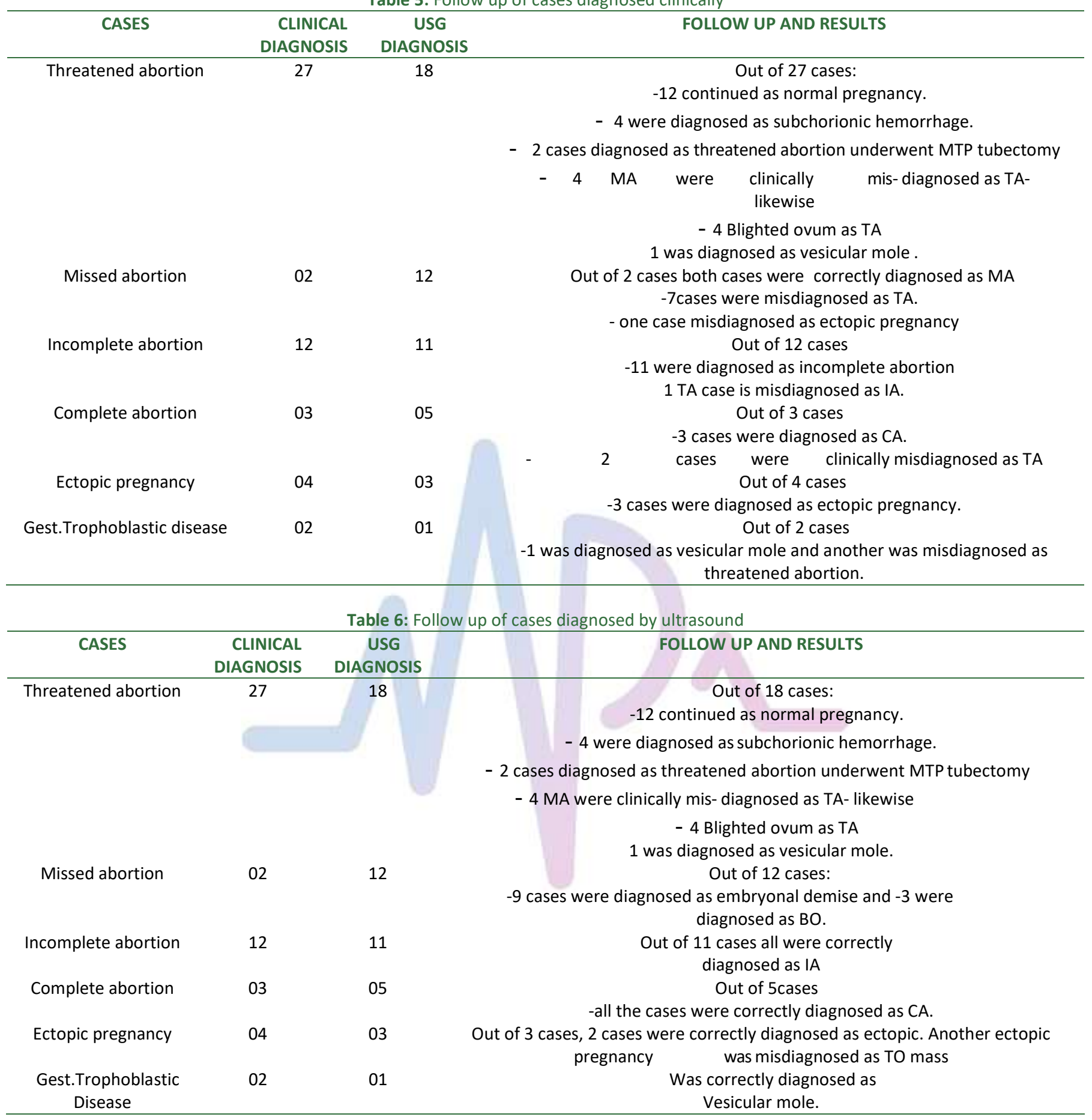

\section{DISCUSSION}

In our study, we have evaluated 50 cases first trimester patients with symptoms to know the role of ultrasound examination versus clinical examination. By mere clinical examination, it was not possible to diagnose many cases correctly. There was disparity of $44.44 \%$ between clinical and ultrasonological diagnosis. Out of the 27 cases which were clinically diagnosed as threatened abortion, only 18 were confirmed as threatened abortion by ultrasound. Ultrasound proved much more accurate than clinical diagnosis with accuracy rate of $100 \%$, while clinical accuracy was $54 \%$. Only 2 cases were clinically diagnosed as missed abortion, but 12 cases were diagnosed by ultrasound as missed abortion. Out of the 12 cases, 9 were 
diagnosed as embryonal demise and 3 were diagnosed as blighted ovum suggesting accuracy rate of $100 \%$. While clinical accuracy is only $4 \%$. Out of the 12 clinically diagnosed cases of incomplete abortions, 11 were diagnosed by ultrasound as incomplete abortion. The clinical accuracy rate is $24 \%$ while ultrasound had an accuracy of $100 \%$. Only 3 cases were clinically diagnosed as complete abortion, but 5 cases were diagnosed by ultrasound as complete abortion suggesting ultrasound accuracy rate of $100 \%$. While clinical accuracy is only 6 $\%$. Of the 4 clinically diagnosed cases of ectopic pregnancy, 3 were diagnosed as ectopic by ultrasound while one case was misdiagnosed as tuboovarian mass. Clinical accuracy was $8 \%$ while ultrasound accuracy was only $70 \%$. Out of the two clinically diagnosed cases of vesicular mole, only one was sonologically diagnosed as vesicular mole with an accuracy rate of $100 \%$. Clinical diagnosis was only $4 \%$ accurate. Similar to our study Joupilla et al. ${ }^{9}$ observed $38 \%$ threatened abortions , $26 \%$ missed abortions, $18 \%$ incomplete abortion, $3 \%$ complete abortion and $1 \%$ gestational trophoblastic disease. In a study by Damania et al. ${ }^{10} 60 \%$ threatened abortion, $15.73 \%$ missed abortion, 5.94\% incomplete abortion, $9.79 \%$ complete abortion, $5.24 \%$ ectopic pregnancy and $3.15 \%$ gestational trophoblastic disease. Raja and Rajan et al. 11 observed maximum $(54.05 \%)$ patients with threatened abortions, $24 \%$ missed abortions, $11.76 \%$ ectopic pregnancy and $35.29 \%$ patients with gestational trophoblastic disease.

Similar to our study, Rama Sofat et al. ${ }^{12}$ observed 50\% patients with threatened abortions, $10 \%$ missed abortions, $2.2 \%$ incomplete abortion, $9 \%$ ectopic pregnancy and $5.5 \%$ gestational trophoblastic disease.

\section{CONCLUSION}

Ultrasonography in present study has helped in establishing a correct diagnosis of $44.44 \%$ of clinically misdiagnosed cases apart from confirming the diagnosis in the rest of the cases.

\section{REFERENCES}

1. Wittels KA, Pelletier AJ, Brown DF, Camargo CA., Jr United States emergency department visits for vaginal bleeding during early pregnancy, 1993-2003. Am J Obstet Gynecol. 2008;198:523.e1-6.

2. Calleja-Agius J. Vaginal bleeding in the first trimester. $\mathrm{Br}$ J Midwifery. 2008;16:656-61.

3. Poulose T, Richardson R, Ewings P, Fox R. Probability of early pregnancy loss in women with vaginal bleeding and a singleton live fetus at ultrasound scan. J Obstet Gynecol. 2006;26:782-4.

4. Schauberger CW, Mathiason MA, Rooney BL. Ultrasound assessment of first-trimester bleeding. Obstet Gynecol. 2005; 105:333-8.

5. Fleischer AC, Andreotti RF, Bohm-Velez M, Fishman EK, Horrow MM, Hricak H. American College of Radiology (ACR) Appropriateness Criteria; 2007. First trimester bleeding; p. 5. Available from: www.acr.org.

6. Luise C, Jermy K, May C, Costello G, Collins WP, Bourne TH. Outcome of expectant management of spontaneousfirst trimester miscarriage: Observational study. BMJ. 2002;324:873-5.

7. Sotiriadis A, Makrydimas G, Papatheodorou S, Ioannidis JP. Expectant, medical, or surgical management of firsttrimester miscarriage: A meta-analysis. ObstetGynecol. 2005; 105:1104-13.

8. Tang OS, Lau WN, Ng EH, Lee SW, Ho PC. A prospective randomized study to compare the use of repeated doses of vaginal with sublingual misoprostol in the management of first trimester silent miscarriages. Hum Reprod. 2003;18:176-81.

9. Joupilla P: Clinical and ultrasonic aspects in the diagnosis and follow up of the patients with early pregnancy failure. Acta.Obstet.Gynaecol.Scand 1980;59:405.

10. Damania K.R, purandare C.B and Daftary S.N. Role of ultrasound in the management of first trimester bleeding. Indian J.Obstet and Gynaecol 1987; 37:195-200.

11. Rajan R, Rajan V. ultrasonography in first trimester bleeding J. Obstet and Gynaecol, India 1987;37:457-46.

12. Rama Sofat R. Ultrasound evaluation of bleeding in early pregnancy. J.Obst and Gynaecology of India 1987;37:344347.

\section{Source of Support: None Declared Conflict of Interest: None Declared}

Policy for Articles with Open Access:

Authors who publish with MedPulse International Journal of Radiology (Print ISSN: 2579-0927) (Online ISSN: 2636-4689) agree to the following terms: Authors retain copyright and grant the journal right of first publication with the work simultaneously licensed under a Creative Commons Attribution License that allows others to share the work with an acknowledgement of the work's authorship and initial publication in this journal.

Authors are permitted and encouraged to post links to their work online (e.g., in institutional repositories or on their website) prior to and during the submission process, as it can lead to productive exchanges, as well as earlier and greater citation of published work. 